\title{
Analysis of Harmonics in Subsea Power Transmission Cables Used in VSC-HVDC Transmission Systems Operating Under Steady-State Conditions
}

\author{
Chang Hsin Chien, Student Member, IEEE, and Richard W. G. Bucknall
}

\begin{abstract}
Subsea power cables are a critical component of a voltage-source converter-high-voltage direct current (VSC-HVDC) transmission system in any offshore electrical power scheme. Subsea cables have complicated structures consisting of many different layers: conductor, insulation, sheath, and armor. Harmonic performance of the system depends upon the interactions between the subsea cable, the power converters, and other system components, such as smoothing capacitors. In this paper, a mathematical model of an HVDC-VSC transmission system is developed and its harmonic performance is investigated for steady-state operating conditions. The results suggest that the design of the subsea transmission cable has important effects on harmonic levels in the voltage and current waveforms in the cable and upon power loss within the transmission system. This paper demonstrates that it is always important to consider interactions between all of the system components when predicting harmonic performance in a VSC-HVDC transmission system.
\end{abstract}

Index Terms-Harmonics, high-voltage direct current (HVDC), offshore, power cable, subsea, voltage-source converter (VSC).

\section{INTRODUCTION}

$\mathbf{T}$ HE methods for interconnecting offshore wind generation farms and onshore utility transmission systems are addressed by Reidy [1]. High-voltage alternating current (HVAC) subsea transmission schemes are commonly used by offshore wind farms (e.g., Horns Rev, Denmark). However, the distances over which ac transmission systems can be used are limited, mainly because of their charging current requirements. High-voltage direct-current (HVDC) schemes offer an alternative method for subsea transmission [2]. There are two categories of HVDC schemes currently available-conventional HVDC and voltage-source converter (VSC)-HVDC. Conventional subsea HVDC transmission schemes employ line-commutated thyristors arranged in back-to-back Graetz bridge networks and these have been installed at many different locations worldwide mainly for interconnecting two shore-based ac networks (e.g., Sellindge to Les Mandarins, the U.K.-France interconnector). For the transmission of power generated offshore, say by a wind farm, the conventional HVDC scheme has several limitations and undesirable characteristics,

Manuscript received July 12, 2006; revised October 10, 2006. This work was supported in part by the BG Group, in part by BP, and in part by Shell. Paper no. TPWRD-00375-2006.

The authors are with the Department of Mechanical Engineering, University College London, London WC1E 7JE, U.K. (e-mail: c_chien@meng.ucl.ac.uk; r_bucknall@meng.ucl.ac.uk).

Digital Object Identifier 10.1109/TPWRD.2007.905277 including being physically large. The VSC-HVDC technology, which utilizes modern semiconductor technologies, such as the insulated-gate bipolar transistor (IGBT), overcomes the disadvantages associated with conventional HVDC transmission for low-power transmission applications and it is therefore more attractive for use with power generation schemes situated far offshore. In VSC-HVDC transmission schemes, pulse-width modulation (PWM) techniques are used, which enables independent control of active and reactive power, a useful feature in ac networks [3], [4].

DC current is transmitted through the subsea cable in a VSC-HVDC scheme. Modulated upon this dc current however are ripples, which originate from the switching behavior of both VSC stations. In previous computer-based harmonic analysis [5], [6] of the voltage and current waveforms in a VSC-HVDC subsea transmission system, the cables have been described as having linear impedance characteristics with frequency. However, offshore transmission cables have a multilayered structure and are heavy armored which gives rise to nonlinear effects, which need to be accounted for. For example, it is reported in [7] that circulating currents in the conducting layers (sheath and armor) give rise to losses in the main conductor and these losses are seen to increase with increases in the circulating current frequency but furthermore the increase is nonlinear. Additionally, inductance in the conducting layers (sheath and armor) reduces the inductance characteristic of the main conductor and again the relationship is nonlinear with frequency.

In order to accurately evaluate how the cable structure influences the harmonic performance characteristics of a VSC-HVDC subsea transmission system, accurate electrical characteristics of the cable are required. An initial approach might be to examine cable models provided in commercially available packages, such as PSCAD/EMTDC, which is a commercially available computer-based simulation tool, providing powerful analysis of multilayer cable models. However, there are limitations with the cable models used by such commercial software packages. For example, it is a common feature that only nonmagnetic material layers are considered; only the outermost conducting layers are bonded to ground, and limited cable arrangements with often only single-core cable models are available for simulation purposes. The aim of this paper has therefore been to investigate the steady-state harmonic behavior of a long-distance VSC-HVDC system when accurate harmonic models for the cables are used. This paper also examines the effects of different subsea cables upon the 


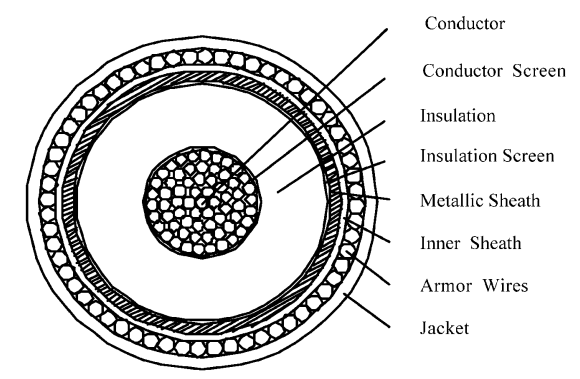

Fig. 1. Typical dc subsea cable cross-section diagram.

performance of a VSC-HVDC system. The results presented here show harmonic resonances and those harmonics present in the waveforms for different operating conditions (e.g., different switching functions, capacitor bank size, cable materials, and transmission methods-monopolar and bipolar arrangements).

\section{Subsea Cable Calculations}

As mentioned earlier, a subsea power cable has a multilayered structure and is generally heavily armored such as that shown in Fig. 1. For dc subsea cables, the insulation is usually designed to withstand higher voltage strengths compared to an equivalent ac subsea cable simply because of the voltage stress requirements. The majority of dc cables in subsea HVDC installations is of the impregnated paper insulated type [8]; however, recent developments in insulation materials have seen the introduction of a PE-based (Polyethylene-based) polymeric insulated cable as tested in a VSC-HVDC offshore transmission scheme [9]. These cable types are now considered as "first choice" by the offshore power generation industry. Multilayer cylindrical construction has been used to determine the subsea cable impedance and admittance [10] with the analysis accounting for the magnetic saturation of the steel armor wires and the conducting layers (e.g., sheath and armor) when bonded at both ends, which is common practice.

The following matrix mathematically describes the relationships between the metallic core, sheath, and armor layers:

$$
\left[\begin{array}{c}
V_{\text {core }} \\
V_{\text {sheath }} \\
V_{\text {armor }}
\end{array}\right]=\left[\begin{array}{lll}
Z_{c c} & Z_{c s} & Z_{c a} \\
Z_{s c} & Z_{s s} & Z_{s a} \\
Z_{a c} & Z_{a s} & Z_{a a}
\end{array}\right]\left[\begin{array}{c}
I_{\text {core }} \\
I_{\text {sheath }} \\
I_{\text {armor }}
\end{array}\right]
$$

where $V_{\text {core }}, V_{\text {sheath }}, V_{\text {armor }}, I_{\text {core }}, I_{\text {sheath }}$, and $I_{\text {armor }}$ are the voltages and currents per-unit length for the core, sheath, and armor, respectively, where

$$
\begin{aligned}
Z_{c c}= & Z_{1}+Z_{2}+Z_{3}-2 Z_{4}+Z_{5} \\
& +Z_{6}+Z_{7}-2 Z_{8}+Z_{9}+Z_{10}+Z_{11}, \\
Z_{s s}= & Z_{5}+Z_{6}+Z_{7}-2 Z_{8} \\
& +Z_{9}+Z_{10}+Z_{11} \\
Z_{a a}= & Z_{9}+Z_{10}+Z_{11} \\
Z_{c s}= & Z_{s c}=-Z_{4}+Z_{5}+Z_{6} \\
& +Z_{7}-2 Z_{8}+Z_{9}+Z_{10}+Z_{11} \\
Z_{c a}= & Z_{a c}=Z_{s a}=Z_{a s} \\
= & -Z_{8}+Z_{9}+Z_{10}+Z_{11}
\end{aligned}
$$

And where $Z_{1}, Z_{5}$, and $Z_{9}$ are the external impedances per-unit length of conductor, sheath, and armor, respectively; $Z_{3}$; and $Z_{7}$ are the internal impedances of the per-unit length of sheath and armor, respectively, and $Z_{4}$ and $Z_{8}$ are the mutual impedances of the per-unit length of sheath and armor, respectively.

The external, internal, and mutual impedances of metallic layers can be formed into the general equations given by [11]

$$
\begin{aligned}
Z_{\text {external }} & =\frac{\rho \sigma}{2 \pi r_{e} H}\left[I 0\left(\sigma r_{e}\right) K 1\left(\sigma r_{i}\right)+K 0\left(\sigma r_{e}\right) I 1\left(\sigma r_{i}\right)\right] \\
Z_{\text {internal }} & =\frac{\rho \sigma}{2 \pi r_{i} H}\left[I 0\left(\sigma r_{i}\right) K 1\left(\sigma r_{e}\right)+K 0\left(\sigma r_{i}\right) I 1\left(\sigma r_{e}\right)\right] \\
Z_{\text {mutual }} & =\frac{\rho}{2 \pi r_{i} r_{e} H} \\
H & =I 1\left(\sigma r_{e}\right) K 1\left(\sigma r_{i}\right)-I 1\left(\sigma r_{i}\right) K 1\left(\sigma r_{e}\right)
\end{aligned}
$$

where $I 0(x)$ and $I 1(x)$ are modified zero-order and first-order Bessel functions with a complex argument; $K 0(x)$ and $K 1(x)$ are modified zero-order and first-order Kelvin functions with a complex argument; and $\sigma=\sqrt{j\left(\omega \mu_{r}\right) /(\rho)}$ is the complex propagation constant in the conducting layers.

And where $\rho$ is the resistivity of the conducting layer, $\omega$ is the angular velocity, $\mu_{r}$ is the permeability of the conducting layer, $r_{i}$ is the internal diameter of the conducting layer, and $r_{e}$ is the external diameter of the conducting layer.

$Z_{2}$ and $Z_{6}$ are the impedances per-unit length of the insulation between core and sheath, and, sheath and armor, respectively, and the impedance of the insulation between two conducting layers can be described by

$$
Z_{\text {insulation }}=j \omega \frac{\mu_{\text {ins }}}{2 \pi} \ln \left(\frac{r_{\text {out }}}{r_{\text {in }}}\right)
$$

where $\mu_{\text {ins }}$ is the permeability of the insulation, $r_{\text {in }}$ is the inside radius of insulation layer, and $r_{\text {out }}$ is the outside radius of the insulation layer.

If the material layer is magnetic, such as steel armor wires, then the magnetic saturation effects need to be accounted for. The relative permeability can be found using longitudinal permeability diagrams of steel wires as explained in [11].

The mutual impedance of the sea return path $Z_{10}$ and selfimpedance of sea return path $Z_{11}$ can be calculated by referring to Wedepohl and Wilcox's equations for earth return impedance of a multilayer cable [12].

For bipolar cables, one cable current will affect the other, simply because the currents are flowing in opposite directions. The sea return mutual impedance $Z_{10}$ and self impedance $Z_{11}$ can be expressed as

$$
\begin{aligned}
& Z_{10}=\frac{-\rho_{\text {sea }} \sigma_{\text {sea }}}{2 \pi r_{i-\text { sea }}}\left[\frac{K 0\left(\sigma_{\text {sea }} \delta\right)}{K 1\left(\sigma_{\text {sea }} r_{i-\text { sea }}\right)}\right] \\
& Z_{11}=\frac{\rho_{\text {sea }} \sigma_{\text {sea }}}{2 \pi r_{i-\text { sea }}}\left[\frac{K 0\left(\sigma_{\text {sea }} r_{i-\text { sea }}\right)}{K 1\left(\sigma_{\text {sea }} r_{i-\text { sea }}\right)}\right]
\end{aligned}
$$

where the negative mutual impedance of the sea return $Z_{10}$ is attributed to the current flowing in the opposite direction in the other cable; $\delta$ is the distance between the two cables; $\rho_{\text {sea }}$ and $\sigma_{\text {sea }}$ are the resistivity and complex propagation constant of the sea, respectively; and $r_{i-\text { sea }}$ is the overall radius of the cable. 
For subsea transmission systems, cables would normally be well bonded with both the sheath and armor layers being connected to earth at each end of the cable. According to [13], the armor of a submarine cable is usually of substantial thickness to prevent flux penetration and the armor can be reasonably assumed to be at ground potential at all points along its length. Similarly, the sheath voltages along a cable's length are insignificant when compared to the voltages of the conductors so these too may be reasonably assumed to be at earth potential along its length

$$
V_{\text {sheath }}=V_{\text {armor }}=0 \text {. }
$$

Adopting this boundary condition, the impedance matrix in (1) can be rewritten as

$$
V_{\text {core }}=Z_{\text {cable }} I_{\text {core }}
$$

where

$$
Z_{\text {cable }}=Z_{c c}+X_{1} Z_{c s}+X_{2} Z_{c a}
$$

where

$$
\begin{aligned}
X_{1} & =\frac{Z_{s a} Z_{a c}-Z_{s c} Z_{a a}}{Z_{s s} Z_{a a}-Z_{s a} Z_{a s}} \\
X_{2} & =\frac{Z_{s c} Z_{a s}-Z_{s s} Z_{a c}}{Z_{s s} Z_{a a}-Z_{s a} Z_{a s}} .
\end{aligned}
$$

In addition to the skin effect in the conductor layer, circulating currents will flow in the metallic sheath and armor also contributing to the total loss in the core. The harmonic resistance and inductance of the core do not have a linear relationship with frequency as is often assumed. Fig. 2 shows the resistance and inductance curves plotted against frequency for a $150-\mathrm{kV}$-rated dc cable whose parameters are given in the Appendix A.

The admittance equation can be expressed as

$$
Y=j \omega \frac{2 \pi \varepsilon_{r}}{\ln \left(\frac{r_{\text {out }}}{r_{\text {in }}}\right)}
$$

where $\varepsilon_{r}$ is the permittivity of the insulation.

Once the impedance and capacitance have been determined, the propagation constant $\gamma$ and the characteristic impedance $Z_{c}$ can be obtained and further evaluations undertaken to determine the frequency and harmonic response.

\section{OFFSHORE POWER VSC-HVDC TRANSMISSION SYSTEMS}

\section{A. Characteristics of VSC-HVDC}

An offshore power VSC-HVDC transmission scheme consists of two VSC stations linked together by dc subsea cables. Referring to the offshore VSC-HVDC transmission described in [14], a simplified transmission diagram is shown in Fig. 3 for convenience where two ac systems are connected via transformers to the supply (generator) and load (network). The development of high-speed gate turn-on and turnoff power-electronic switching devices, such as the insulated-gate bipolar transistor (IGBT) and gate turnoff (GTO) thyristors, has resulted in PWM switching techniques being adopted by the converters to control both the output voltage and output frequency.

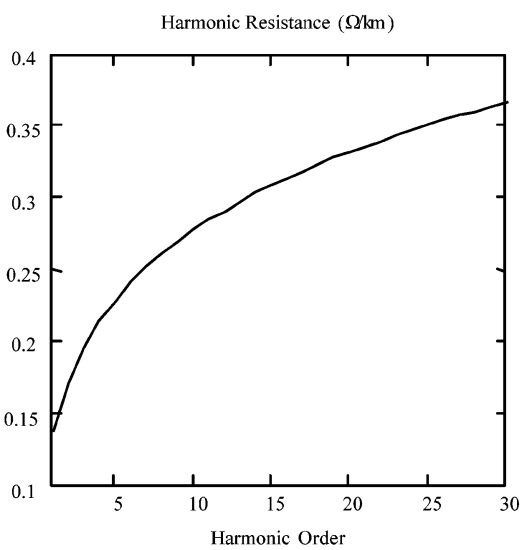

Harmonic Inductance $(\mathrm{mH} / \mathrm{km})$

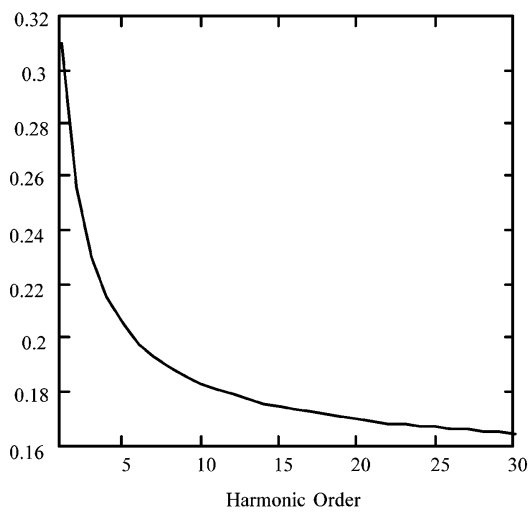

Fig. 2. Harmonic resistance and inductance per kilometer of subsea cable.

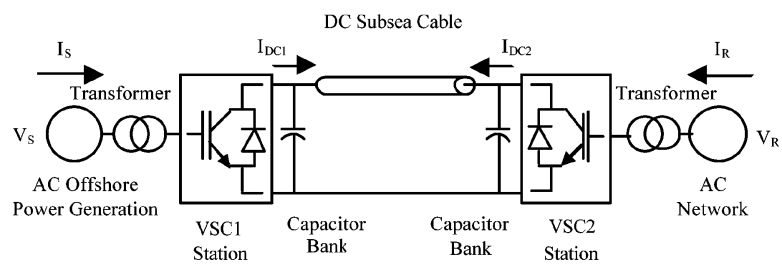

Fig. 3. Offshore power VSC-HVDC transmission configuration.

The converter switching frequency is substantially higher than the fundamental supply current frequency. The PWM switching techniques control the magnitude and the phase of the output voltage of the VSC by determining the points of turn on and turn off and, hence, the conduction periods of each semiconductor switch. The switching points are effectively determined by the points of intersection of a carrier waveform (typically a triangular waveform) and modulation signal within the converter control system [15], [16]. It is the switching of the semiconductor switches that generates the harmonics in the transmission system. For the purpose of the harmonic study, the harmonic-domain (HD) vector, as explained in Appendix B, is used to represent the equations. The three-phase voltage supply and output current for the VSC can be expressed as

$$
\begin{aligned}
& \mathbf{V}_{\mathrm{a}}=\mathbf{S}_{\mathrm{ab}} \mathbf{V}_{\mathrm{dc}}, \quad \mathbf{V}_{\mathrm{b}}=\mathbf{S}_{\mathrm{bc}} \mathbf{V}_{\mathrm{dc}}, \quad \mathbf{V}_{\mathbf{c}}=\mathbf{S}_{\mathrm{ca}} \mathbf{V}_{\mathrm{dc}} \\
& \mathbf{I}_{\mathrm{dc}}=\mathbf{S}_{\mathrm{ab}} \mathbf{I}_{\mathrm{a}}+\mathbf{S}_{\mathrm{bc}} \mathbf{I}_{\mathrm{b}}+\mathbf{S}_{\mathrm{ca}} \mathbf{I}_{\mathrm{c}}
\end{aligned}
$$




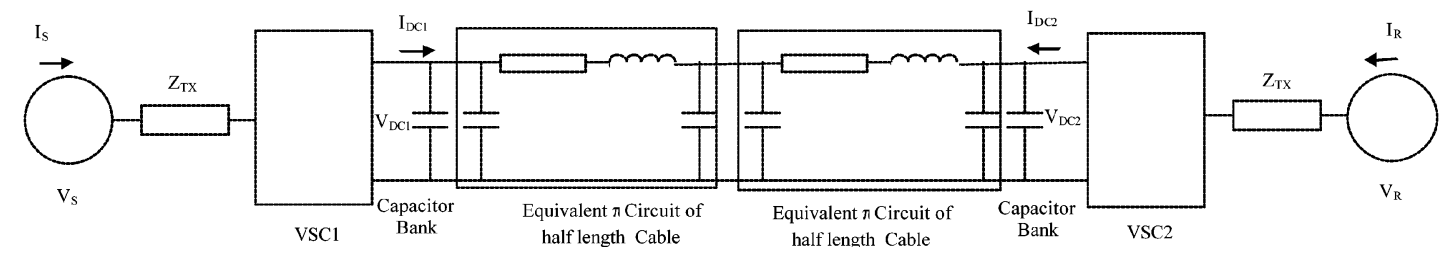

Fig. 4. Combination of two models of VSC with a half length of cable.

where $\mathbf{V}_{\mathbf{d c}}$ and $\mathbf{I}_{\mathbf{d c}}$ are the harmonic vectors of the dc link voltage and current, respectively. The operation of the PWM switching functions $\mathbf{S}_{\mathbf{a b}}, \mathbf{S}_{\mathbf{b c}}$ and $\mathbf{S}_{\mathbf{c a}}$ are Toeplitz matrices containing the harmonic contents for the three-phase six-pulse VSC converters as described in [5] and [17]. $\mathbf{V}_{\mathbf{a}}, \mathbf{V}_{\mathbf{b}}$ and $\mathbf{V}_{\mathbf{c}}$ are the harmonic vectors of the phase voltages and $\mathbf{I}_{\mathbf{a}}, \mathbf{I}_{\mathbf{b}}$, and $\mathbf{I}_{\mathbf{c}}$ are the harmonic vectors of the phase currents.

\section{B. Steady-State Control}

The control strategy usually adopted is to use one of the VSCs as the power dispatcher and the other as the voltage regulator. The power dispatcher supplies the active power $P_{\mathrm{vsc}}$ for a given reference power $P_{\text {ref }}$ with the closed-loop feedback error signal $\varepsilon_{p}$ applied to vary the power until zero error is achieved

$$
\varepsilon_{p}=P_{\mathrm{vsc}}-P_{\text {ref }}
$$

The other VSC is used as a voltage regulator to maintain the dc voltage $V_{\mathrm{vscDC}}$ for a given reference voltage $V_{\text {ref }}$ and the feedback error signal $\varepsilon_{v}$ is applied until zero error is achieved

$$
\varepsilon_{v}=V_{\mathrm{ref}}-V_{\mathrm{vscDC}} .
$$

In practice, the steady-state voltage of the dc link is achieved by adjusting the conducting periods of the VSC switching devices and under steady voltage conditions, no dc current will flow into the capacitor banks as explained in [5]

$$
I_{\mathrm{DC} 10}+I_{\mathrm{DC} 20}=0
$$

where $I_{\mathrm{DC} 10}$ is the dc term of the $\mathbf{I}_{\mathbf{D C} \mathbf{1}}$ harmonic vector and $I_{\mathrm{DC} 20}$ is the dc term of the $\mathbf{I}_{\mathbf{D C} 2}$ harmonic vector.

Obtaining the conduction periods for the steady-state conditions mathematically becomes an iterative process. The relationship between phase angle and dc current can be considered to be a linear one [18].

\section{Calculations Model for Harmonic Analysis}

The harmonic calculation model for the VSC-HVDC station is developed in [18] and validated by PSCAD/EMTDC. For the transmission system, the model can be regarded as being a combination of two VSC converter station models with a cable linking the converters. A complete VSC-HVDC subsea monopolar transmission model is represented in Fig. 4, where the subsea cable model is divided into two half-length equivalent $\pi$ circuits.

The harmonic equations that represent the VSC-HVDC transmission system shown in Fig. 4 are

$$
\left[\begin{array}{l}
\mathbf{V}_{\mathbf{S T}} \\
\mathbf{V}_{\mathbf{R T}}
\end{array}\right]=\left[\begin{array}{ll}
\mathbf{A} & \mathbf{B} \\
\mathbf{C} & \mathbf{D}
\end{array}\right]\left[\begin{array}{l}
\mathbf{I}_{\mathbf{S}} \\
\mathbf{I}_{\mathbf{R}}
\end{array}\right]
$$

where

$$
\begin{aligned}
\mathbf{V}_{\mathbf{S T}} & =\mathbf{V}_{\mathbf{S}}-\mathbf{Z}_{\mathbf{G}} \mathbf{I}_{\mathbf{S}}-\mathbf{P}_{\mathbf{S} 1} V_{\mathrm{DC} 10} \\
\mathbf{V}_{\mathbf{R T}} & =\mathbf{V}_{\mathbf{R}}-\mathbf{Z}_{\mathbf{G}} \mathbf{I}_{\mathbf{R}}-\mathbf{P}_{\mathbf{S} \mathbf{2}} V_{\mathrm{DC} 20}
\end{aligned}
$$

where $V_{\mathrm{DC} 10}$ and $V_{\mathrm{DC} 20}$ are the de terms of $\mathbf{V}_{\mathbf{D C 1}}$ and $\mathbf{V}_{\mathbf{D C} \mathbf{2}}$ harmonic vectors, respectively. Also, by taking into account the power losses in the cable, then

$$
V_{\mathrm{DC} 20}=V_{\mathrm{DC} 10}-R_{\text {cable }} I_{\mathrm{DC} 10}
$$

$\mathbf{Z}_{\mathbf{G}}$ are the harmonic vectors of initial impedance of the ac source. The switching functions for VSC1 and VSC2 of threephase transformation matrices $\mathbf{S}_{\mathbf{C}}$ and $\mathbf{S}_{\mathbf{R}}$ can be expressed as

$$
\begin{aligned}
\mathbf{S}_{\mathbf{C}} & =\left[\begin{array}{l}
\mathbf{S}_{\mathrm{ab}} \\
\mathbf{S}_{\mathrm{bc}} \\
\mathbf{S}_{\mathrm{ca}}
\end{array}\right] \\
\mathbf{S}_{\mathbf{R}} & =\left[\begin{array}{lll}
\mathbf{S}_{\mathbf{a b}} & \mathbf{S}_{\mathrm{bc}} & \mathbf{S}_{\mathbf{c a}}
\end{array}\right] .
\end{aligned}
$$

The $\mathbf{A}, \mathbf{B}, \mathbf{C}$, and $\mathbf{D}$ in the transformation matrix are given

$$
\begin{aligned}
& \mathbf{A}=\mathbf{Z}_{\mathbf{T X}}+\frac{1}{2} \mathbf{S}_{\mathbf{C} 1} \mathbf{A}_{\mathbf{C}}\left(\mathbf{Y}_{\mathbf{C A P}} \mathbf{A}_{\mathbf{C}}+\mathbf{C}_{\mathbf{C}}\right)^{-1} \mathbf{S}_{\mathbf{R} \mathbf{1}} \\
& +\frac{1}{2} \mathbf{S}_{\mathrm{C} 1} \mathbf{B}_{\mathrm{C}}\left(\mathrm{D}_{\mathrm{C}}+\mathbf{Y}_{\mathrm{CAP}} \mathbf{B}_{\mathrm{C}}\right)^{-1} \mathbf{S}_{\mathrm{R} 1} \\
& \mathrm{~B}=\frac{1}{2} \mathbf{S}_{\mathbf{C} 1} \mathbf{A}_{\mathbf{C}}\left(\mathbf{Y}_{\mathbf{C A P}} \mathbf{A}_{\mathrm{C}}+\mathbf{C}_{\mathbf{C}}\right)^{-1} \mathbf{S}_{\mathbf{R} 2} \\
& -\frac{1}{2} \mathbf{S}_{\mathrm{C} 1} \mathbf{B}_{\mathrm{C}}\left(\mathrm{D}_{\mathrm{C}}+\mathbf{Y}_{\mathrm{CAP}} \mathrm{B}_{\mathrm{C}}\right)^{-1} \mathbf{S}_{\mathbf{R} 2} \\
& \mathrm{C}=\frac{1}{2} \mathbf{S}_{\mathrm{C} 2} \mathbf{A}_{\mathbf{C}}\left(\mathbf{Y}_{\mathbf{C A P}} \mathbf{A}_{\mathrm{C}}+\mathbf{C}_{\mathbf{C}}\right)^{-1} \mathbf{S}_{\mathbf{R} 1} \\
& -\frac{1}{2} \mathbf{S}_{\mathrm{C} 2} \mathbf{B}_{\mathrm{C}}\left(\mathbf{D}_{\mathrm{C}}+\mathbf{Y}_{\mathbf{C A P}} \mathbf{B}_{\mathrm{C}}\right)^{-1} \mathbf{S}_{\mathbf{R} 1} \\
& \mathbf{D}=\mathbf{Z}_{\mathbf{T X}}+\frac{\mathbf{1}}{\mathbf{2}} \mathbf{S}_{\mathbf{C} \mathbf{2}} \mathbf{A}_{\mathbf{C}}\left(\mathbf{Y}_{\mathbf{C A P}} \mathbf{A}_{\mathbf{C}}+\mathbf{C}_{\mathbf{C}}\right)^{-\mathbf{1}} \mathbf{S}_{\mathbf{R} 2} \\
& +\frac{1}{2} \mathbf{S}_{\mathbf{C} 2} \mathbf{B}_{\mathbf{C}}\left(\mathbf{D}_{\mathrm{C}}+\mathbf{Y}_{\mathbf{C A P}} \mathbf{B}_{\mathbf{C}}\right)^{-1} \mathbf{S}_{\mathbf{R} 2}
\end{aligned}
$$

where $\mathbf{Z}_{\mathbf{T X}}$ is the harmonic vector of impedance of transformers, $\mathbf{Y}_{\mathbf{C A P}}$ is the harmonic vector of admittance for the capacitor banks and the cable transformation functions $\mathbf{A}_{\mathbf{C}}, \mathbf{B}_{\mathbf{C}}, \mathbf{C}_{\mathbf{C}}$, and $\mathbf{D}_{\mathbf{C}}$ are given as follows:

$$
\begin{aligned}
& \mathbf{A}_{\mathbf{C}}=\cosh (\gamma L / 2) \\
& \mathbf{B}_{\mathbf{C}}=\mathbf{Z}_{\mathbf{C}} \cosh (\boldsymbol{\gamma} L / 2) \\
& \mathbf{C}_{\mathbf{C}}=\frac{\mathbf{1}}{\mathbf{Z}_{\mathbf{C}}} \sinh (\boldsymbol{\gamma} L / 2) \\
& \mathbf{D}_{\mathbf{C}}=\cosh (\gamma L / 2)
\end{aligned}
$$

where $L$ is the length of the cable, $\gamma=\sqrt{\mathbf{Z}_{\text {cable }} \mathbf{Y}_{\text {cable }}}$ is the harmonic vector of the cable propagation constant, 
$\mathbf{Z}_{\mathbf{C}}=\sqrt{\mathbf{Z}_{\text {cable }} / \mathbf{Y}_{\text {cable }}}$ is the harmonic vector of the characteristic impedance and the cable impedance per-unit length in harmonic domain $\mathbf{Z}_{\text {cable }}$ and cable admittance per-unit length in harmonic domain $\mathbf{Y}_{\text {cable }}$ are acquired using the equations for subsea cables as presented earlier in Section II.

\section{RESONANCE ANALYSIS}

The VSC-HVDC system used for the case study has the parameters given as follows: AC voltage sources are 150 $\mathrm{kV}$, having $\mathrm{R}-\mathrm{L}$ parallel equivalent initial impedance where $R_{G}=1 \Omega$ and $L_{G}=0.01 \mathrm{H}$. The two transformers have series impedances described as $R_{\mathrm{TX}}=5 \Omega$ and $L_{\mathrm{TX}}=0.2 \mathrm{H}$. Both capacitor banks are $50 \mu \mathrm{F}$. For two VSCs with a fundamental frequency of $50 \mathrm{~Hz}$, three-level and six-pulse VSCs are used with a switching frequency of $250 \mathrm{~Hz}$, which is adopted here after referring to [5], a study of PWM switching techniques in HVDC systems. Should higher switching frequencies be employed, then the methods reported here remain appropriate and could equally be used to analyze harmonic performance. A modulation index of 0.9 has been chosen where VSC1 is selected as the voltage regulator to maintain the dc link at 150 $\mathrm{kV}$ and VSC2 is selected as a 300-MW power dispatcher. DC subsea cable parameters and size are given in the Appendix A whose resistance under operating temperature $90^{\circ} \mathrm{C}$ is 0.02 $\Omega / \mathrm{km}$. The sine-triangular modulation technique [17] is used for PWM switching where the switching frequency of carrier signal is $f_{r}$ and the frequency of modulation signal is $f_{s}$ is $50 \mathrm{~Hz}$ for this case and the frequency-modulation ratio $m_{f}$ is given as

$$
m_{f}=\frac{f_{r}}{f_{s}} .
$$

When considering a VSC-HVDC transmission system, the harmonic amplitudes will be influenced by the cable harmonic resonant characteristics. The equivalent impedance of the dc side of the transmission system needs to take into account both the cable and the dc capacitors, which constitute part of the admittance shunt. The harmonic vector of equivalent impedance $\mathbf{Z}_{\mathbf{e q}}$ is given as

$$
\begin{aligned}
\mathbf{Z}_{\mathbf{e q}} & =\frac{\mathbf{Y}_{\mathbf{p}} \cdot\left(\mathbf{Z S}+\frac{1}{\mathbf{Y}_{\mathbf{p}}}\right)}{\mathbf{Y}_{\mathbf{p}}+\left(\mathbf{Z S}+\frac{1}{\mathbf{Y}_{\mathbf{p}}}\right)} \\
\mathbf{Y}_{\mathbf{p}} & =\mathbf{Y}_{\mathbf{C A P}}+\mathbf{Y S} \\
\mathbf{Z S} & =\mathbf{Z}_{\mathbf{C}} \cdot \sinh (\gamma L) \\
\mathbf{Y S} & =\frac{1}{\mathbf{Z}_{\mathbf{C}}} \tanh \left(\frac{\gamma L}{2}\right) .
\end{aligned}
$$

The equivalent impedance from the sending end is shown in Fig. 5 for up to 30 harmonic orders. The resonances for the different lengths of a dc cable are also identified. The greatest values of equivalent impedance are at the fundamental frequency and the amplitude reduces as frequency increases as would be expected. Resonances are seen to take place as the frequency is increased but the magnitudes are not as high as the value at the fundamental frequency. Comparing the resonances for different lengths of cable, then generally the resonance occurs at higher frequencies as the cable length is shortened.

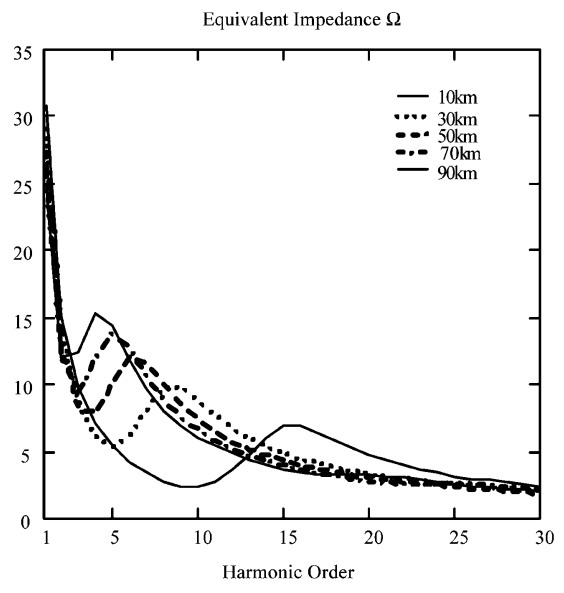

Fig. 5. DC side of VSC-HVDC equivalent impedance response.

The magnitudes of the resonances are generally less in the longer cables. Generally, the resonance of the dc transmission side is less significant for subsea cables than those in overhead transmission lines [19], which usually have high peaks at high frequencies.

\section{HARMONIC ANALYSIS OF THE VSC-HVDC SUBSEA TRANSMISSION UNDER DIFFERENT OPERATION CONDITIONS}

The next step is to study harmonic behavior for different arrangements so as to understand how subsea cables influence the harmonic behavior in a VSC-HVDC transmission system.

\section{A. Switching Frequency Effect}

Simulation results for the case study are acquired in the harmonic domain; hence, the inverse fast Fourier transform (IFFT) has been used in order to obtain both the waveforms on the ac and de sides. It should be noted that had the higher-order harmonics been included in the analysis (i.e., up to the 100th order), the represented waveform would be more representative. However, the 30th order is sufficiently accurate and computationally efficient. Fig. 6 shows the waveforms of the dc voltage $V_{\mathrm{DC} 1}$ and the ac current $I_{S}$ containing harmonics of the 30th order in the dc link at the sending end of the transmission system. The frequency-modulation ratio $m_{f}$ was set to 5 (i.e., the switching frequency was $250 \mathrm{~Hz}$ for reasons discussed earlier). As expected, there are ripples in the dc waveform that are generated by low-order harmonics with the voltage regulator VSC1 keeping the average voltage at $150 \mathrm{kV}$ with a fluctuation of $\pm 10 \mathrm{kV}$. Also evident are the harmonic distortions present in the ac current which can be attributed to the converter switching, which are close to the fifth order at $250 \mathrm{~Hz}$.

When the switching frequency is increased, then the harmonics shift to higher frequencies but the principles of analysis remain the same. The switching functions in the VSC are the main source of harmonics on both sides of the VSC. Fig. 7 shows the response to the 30th harmonic order with the switching frequency being varied as $m_{f}=5,7,9,11$, and 13 for $250,350,450,550$, and $650 \mathrm{~Hz}$, respectively, and with the harmonics on both the ac and dc sides changing accordingly. The results show that the ac current harmonics have the greatest magnitude when the harmonics are at the switching 

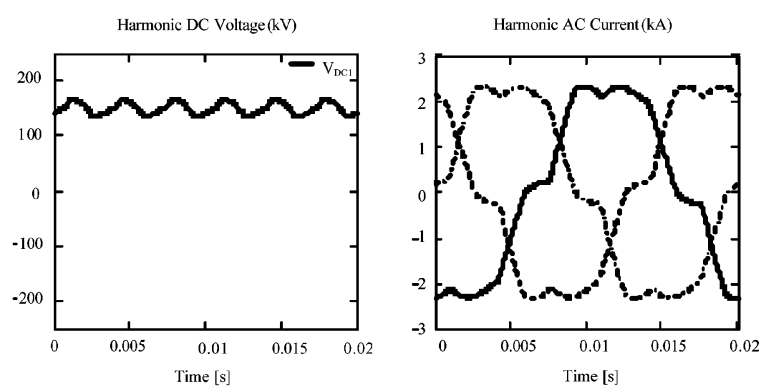

Fig. 6. Voltage of the dc side and current of the ac side on the sending end.

frequency; For instance, the greatest harmonics under different switching frequencies are the 5 th harmonic for $m_{f}=5$, the 7th harmonic for $m_{f}=7$, the 11th harmonic for $m_{f}=11$, and the 13th harmonic for $m_{f}=13$. However, when $m_{f}=9$, then due to no characteristic harmonics being generated at this frequency, the nearest harmonics 7 th and 11th are shown to be the greatest. To consider the harmonics on the dc side then, there are $6 \mathrm{n}(\mathrm{n}=1,2,3 \ldots)$ orders of harmonic generated in Fig. 7. The same phenomenon is seen to occur in the voltage on the dc side of the VSC where the harmonic magnitudes are higher when they get close to the switching frequency. It is evident therefore that the PWM switching frequency is a key factor that determines the amplitudes and frequencies of the harmonic generated on both the ac and dc sides in an offshore VSC-HVDC transmission system.

\section{B. Capacitor Bank Effect}

The capacitance of subsea cable is considerable and it provides a capacitance shunt that can be exploited to reduce the size of the dc capacitor bank required for providing dc voltage stability and for filtering out the switching noise in an HVDC transmission system [6]. Fig. 8 shows the dc and ac side total harmonic distortion (THD) at the sending end and also power losses against the length of cable for different sizes of capacitor banks. For dc-side voltage THD, it is obvious that as the capacitor bank is increased, the THD is significantly reduced, implying that the capacitor bank stabilizes the dc voltage, agreeing with the observations given in [6]. For dc-side current THD, then as the capacitor bank is increased, the resonances, which are produced by the interaction of the dc current harmonics with the system itself, are gradually reduced and eventually become insignificant. The results indicate that the resonances on the dc side are attributed to the cable and capacitor banks and these diminished as the capacitor bank size increased. For the ac-side current harmonics, then when using a capacitor bank $\mathrm{c}=50 \mu \mathrm{F}$, the resonance takes place at $50 \mathrm{~km}$. However, when the capacitor bank is increased, the resonance becomes damped such as is seen for values of $\mathrm{c}=100 \mu \mathrm{F}$ and $\mathrm{c}=500 \mu \mathrm{F}$. In terms of magnitude, the range for these cases extends from $16.9 \%$ up to $17.8 \%$, and does not significantly fluctuate along the cable length. Power losses, which are the major concern for efficiency, need to account for the harmonic resonances against the cable length. The peak for $\mathrm{c}=50 \mu \mathrm{F}$ is $45.4 \%$ at $54 \mathrm{~km}$, which is $12.5 \%$ higher than the peak for $\mathrm{c}=100 \mu \mathrm{F}$ which is $32.9 \%$ at $27 \mathrm{~km}$. Also, as the capacitor bank size is increased, the resonances are generally more damped and losses are reduced. These results suggest
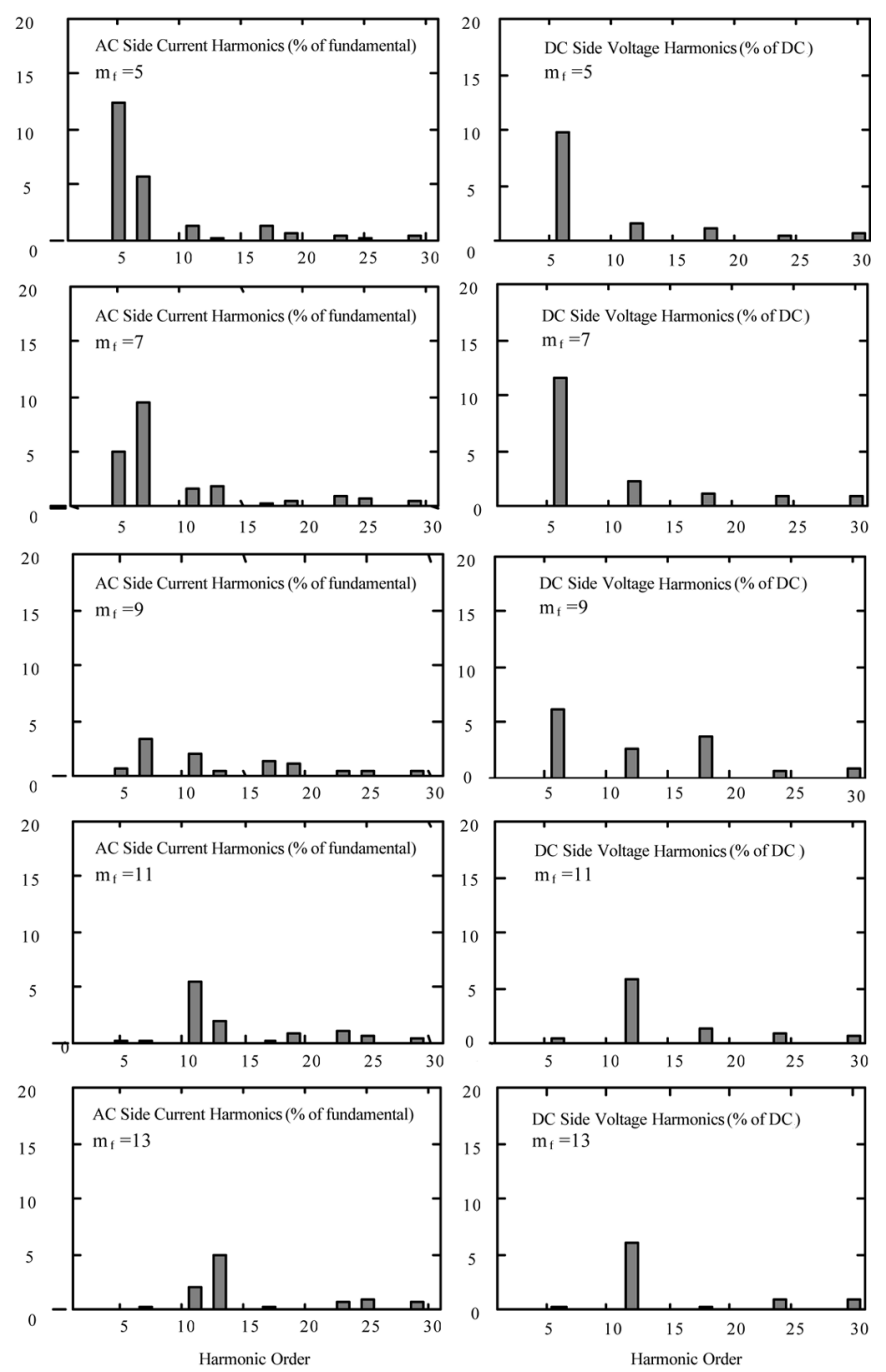

Fig. 7. AC-side current harmonic and dc-side voltage harmonic under a different switching frequency.

that the losses are not only contributed by cable resistance and converter operation but are also due to the level of harmonics. It is important that the resonances of the power loss for a specific cable length be detected to avoid excessive loss.

\section{Cable Material Effect}

Subsea cables use a diverse range of materials. Apart from XLPE insulation, which has been recently developed for dc subsea cables, paper-impregnated insulation is widely used because of its ability to withstand high-voltage stress. The permeability of steel armor is dependent on the alignment of steel wires since only longitudinal laid wires contribute to the permeability of the cable [11]; whether or not these steel wires are touching each other and the type of steel used. Also, copper wire can be selected as an alternative to steel armor. The relative permeability of steel wire can range from 10 to 300 [11]. For the purpose of comparison, steel armor with 10 and 100 relative permeability was used in the simulations; $\mu_{r}=10$ and $\mu_{r}=100$. Analysis was also carried out using cables with XLPE insulation and paper insulation and copper armor and their effects on HVDC system harmonics were 

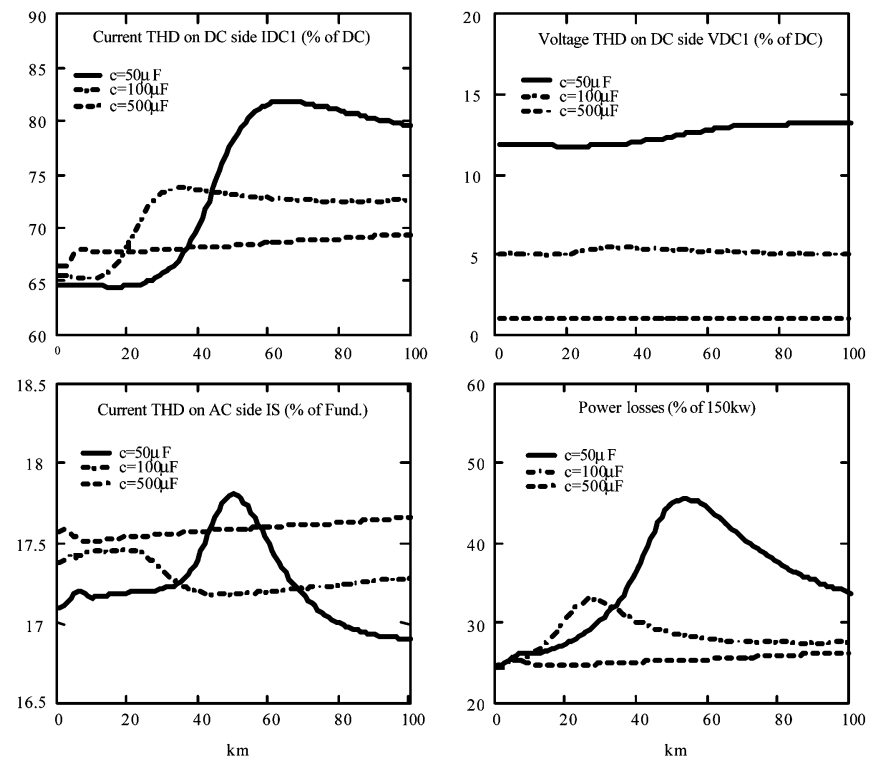

Fig. 8. AC-side and dc-side THD and power losses.

investigated. Fig. 9 shows that generally the harmonics on both the ac and dc sides and the transmission power losses for the paper-impregnated insulation cable, whose relative permittivity is 3.6, is not much different from the XLPE insulation cable, whose relative permittivity is 2.5 . This is because of the change of the permittivity, which, in turn, produces a difference in capacitance in the two cable designs, is relatively insignificant when contrasted to the capacitance provided by the capacitance banks. However, in terms of the permeability, the cable with steel armor of $\mu_{r}=100$ has less amplitudes of resonance along the cable length compared to the cable with steel armor of $\mu_{r}=10$, on both the dc and ac sides. Furthermore, when the armor material is changed from steel to copper, the harmonic amplitudes on both the ac and dc sides tend to reduce and the power losses steadily increase as the cable lengths increase, with no obvious resonance, which apparently occurs in the case of the cable with steel armor wires. Due to armor impedance being affected by the permeability and large impedance differences between the steel armor and copper armor, these, in turn, influence impedance cancellation between layers, the cable characteristics interact with the transmission system and provide distinct harmonic resonances for variations in cable length.

\section{Bipolar Transmission Effect}

For VSC-HVDC transmission, bipolar transmission is often preferred [3]. For the purposes of analysis, a 150-kV transmission system is designed as a bipolar transmission system with \pm 75 -kV-rated cable using two identical cables placed $5 \mathrm{~m}$ apart; one carrying the load current and the other carrying the return current. To allow comparison with the monopolar arrangement, the cross section of two cable conductors was designed with the same cross-sectional area of $1000 \mathrm{~mm}^{2}$ but with the insulation thickness being $10 \mathrm{~mm}$ instead of $17 \mathrm{~mm}$ as used in the $150-\mathrm{kV}$ monopolar cable, because of the reduced insulation requirement. The cable parameters and dimensions are described
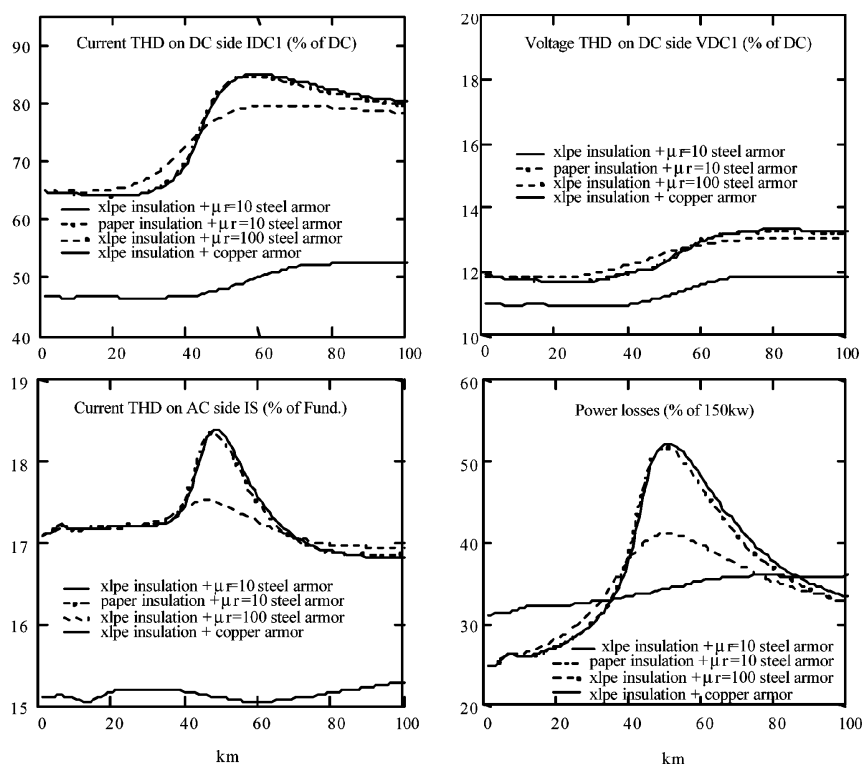

Fig. 9. AC-side and DC-side THD and power losses under different cable materials.
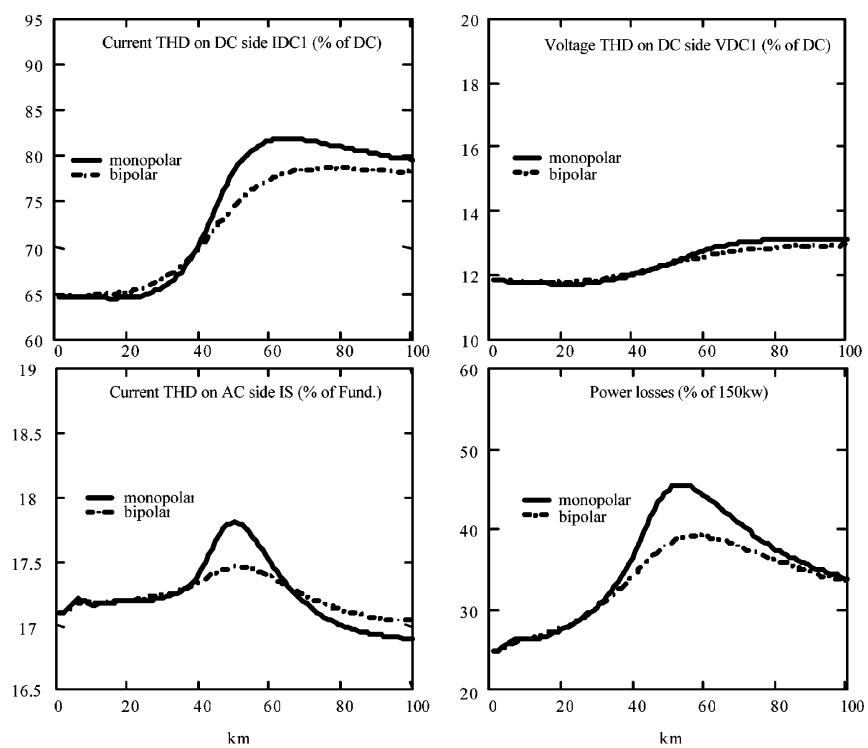

Fig. 10. AC-side and dc-side THD and power losses of monopolar and bipolar transmission.

in Appendix C. Considering the results of the analysis in Fig. 10, there are then clear differences in harmonic behavior and power loss when the two transmission methods are compared. For the bipolar cable, there are two cables carrying current in opposite directions which influences the mutual impedance of the sea return path in (8). The bipolar arrangement and the thinner cable insulation have an effect on the system harmonics giving a different response to that found in the monopolar system. The harmonic resonances of the bipolar arrangement, when plotted against cable length, tend to be less sharp. Also, the power loss due to the resonance for bipolar transmission is damped in comparison with the monopolar arrangement, because losses from the harmonic are less in bipolar transmission. 


\section{CONCLUSION}

In this paper, investigations using computer simulation of harmonic performance of VSC-HVDC models under the steadystate condition have been investigated using improved cable models. The study has shown that accurate subsea cable models are necessary, and appropriate mathematical models are presented here which are used to predict the resonance of the cable along its length in a VSC-HVDC system. From the switching frequency aspect, then if the switching frequency avoids the characteristic resonance harmonics on both ac and dc side, then the level of harmonics will be reduced. From the capacitor bank point of view, an increase of the capacitor bank size dampens the resonance. By changing insulation and armor material of the dc cable, the harmonic response was much less distinct between the XLPE insulation and paper-impregnated insulation. However, the permeability of steel wires is an essential factor influencing harmonic performance, and there is also a distinct difference in harmonic performance between steel-armored cables and copper-armored cables. For bipolar transmission, due to thinner insulation requirements and a second cable carrying the return current in the opposite direction, the harmonics are damped and there is reduced power loss within the subsea transmission system.

This study contributes toward an insight of how subsea cables influence the harmonic of the VSC-HVDC system in a transmission system. It implies that the subsea cable model needs to be carefully assessed in order to represent the harmonic behavior in the subsea VSC-HVDC transmission system. Also, to understand the harmonic behavior and harmonic distortion, power loss must be considered as this is critical to the design of offshore power transmission systems.

\section{APPENDIX A \\ DIMENSION OF THE 150-KV DC CABLE}

Copper conductor diameter: $37.9 \mathrm{~mm}$;

XLPE insulation thickness: $17 \mathrm{~mm}$;

Permittivity of XLPE $2.5 \times$ air permittivity;

Diameter over insulation: $78.5 \mathrm{~mm}$;

Lead sheath thickness: $2.5 \mathrm{~mm}$;

Outer diameter of cable: $102.2 \mathrm{~mm}$;

Steel wire number: 54 ;

Steel wire diameter: $5 \mathrm{~mm}$.

\section{APPENDIX B \\ HARMONIC-DOMAIN VECTOR}

The harmonic domain [5] is built using the complex Fourier series as a periodic function $f(t)$ given as

$$
f(t)=\sum_{h=-\infty}^{\infty} F_{h} e^{j h \omega_{0} t}
$$

where $h$ is the harmonic order and $\omega_{0}$ is the angular velocity at fundamental frequency. To represent the harmonic domain using a vector approach

$$
\mathbf{F}=\left[\begin{array}{lllllllll}
\cdots & F_{-3} & F_{-2} & F_{-1} & F_{0} & F_{1} & F_{2} & F_{3} & \cdots
\end{array}\right]^{T}
$$

where $\mathbf{F}$ is the vector with harmonic content for each order including a de term $F_{0}$.

\section{APPENDIX C \\ DIMENSION OF THE 75-KV DC CABLE}

Copper conductor diameter: $37.9 \mathrm{~mm}$;

XLPE insulation thickness: $10 \mathrm{~mm}$;

Permittivity of XLPE $2.5 \times$ air permittivity;

Diameter over insulation: $61.3 \mathrm{~mm}$;

Lead sheath thickness: $2.5 \mathrm{~mm}$;

Outer diameter of cable: $88.2 \mathrm{~mm}$;

Steel wire number: $\quad 49$;

Steel wire diameter: $5 \mathrm{~mm}$.

\section{ACKNOWLEDGMENT}

The authors would like to thank Dr. M. Madrigal at the Instituto Tecnológico de Morelia, Morelia, Mexico, for his helpful comments and suggestions.

\section{REFERENCES}

[1] A. Reidy and R. Watson, "Comparison of VSC based HVDC and HVAC interconnections to a large offshore wind farm," in Proc. IEEE Power Eng. Soc. General Meeting, Jun. 2005, pp. 71-78.

[2] "Limitation of long transmission cables for offshore wind farms," 2003, copyright produced by ESS, Inc., consultants to Cap Wind Associates, LLC.

[3] T. Ackermann, "Transmission systems for offshore wind farms," IEEE Power Eng. Rev., vol. 22, no. 12, pp. 23-27, Dec. 2002.

[4] M. Yin, G. Li, M. Zhou, Y. Liu, and Y. Liu, "Analysis and control of wind farm incorporated vsc-HVDC in unbalanced conditions," in Proc. IEEE/Power Eng. Soc. Transmission and Distribution Conf. Exhibit.: Asia Pacific, Aug. 2005, pp. 1-6.

[5] M. Madrigal and E. Acha, "Harmonic modelling of voltage source converters for HVDC stations," in Proc. Inst. Elect. Eng., AC-DC Power Transmission Conf., Nov. 2001, pp. 169-174, Publ. No. 485.

[6] Z. Yao and B. T. Ooi, "Utilization of cable capacitance in GTO-HVDC transmission," IEEE Trans. Power Del., vol. 13, no. 3, pp. 945-951, Jul. 1998.

[7] Z. H. Yuan and Y. Du, "Harmonic impedance of single-core armoured cables," in Proc. IEEE Power Eng. Soc. Transmission and Distribution Conf. Expo., Sep. 2003, vol. 1, pp. 45-48.

[8] O. I. Gelbertson, Electrical Cables for Power and Signal Transmission. New York: Wiley, 2000, pp. 247-253.

[9] B. Normark and E. K. Nielsen, "Advanced power electronics for cable connection of offshore wind," presented at the Copenhagen Offshore Wind, Copenhagen, Denmark, 2005.

[10] A. Ametani, "A general formulation of impedance and admittance of cables," IEEE Trans. Power App. Syst., vol. PAS-99, no. 3, pp. 902-910, May/Jun. 1980.

[11] G. Bianchi and G. Luoni, "Induced currents and losses in single-core submarine cables," IEEE Trans. Power App. Syst., vol. PAS-95, no. 1, pp. 49-57, Jan./Feb. 1976.

[12] L. M. Wedepohl and D. J. Wilcox, "Transient analysis of underground power-transmission systems; system model and wave-propagation characteristics," Proc. Inst. Elect. Eng., Gen., Transm. Distrib., vol. 120, no. 2, pp. 253-260, Feb. 1973.

[13] B. Gustavsen, J. A. Martinez, and D. DurbakIEEE Power Eng. Soc. Task Force on Data for Modeling System Transients of IEEE Power Eng. Soc. Working Group on Modeling and Analysis of System Transients Using Digital Simulation (General Systems Subcommittee), "Parameter determination for modeling system transients-Part II: Insulated cables," IEEE Trans. Power Del., vol. 20, no. 3, pp. 2045-2050, Jul. 2005.

[14] M. Hyttinen and K. Bentzen, "Operating experiences with a voltage source converter (HVDC-light) on the gas platform troll A," presented at the Energex Int. Conf. Exhibit., Stavanger, Norway, Jun. 2006.

[15] W. Lu and B. T. Ooi, "Optimal acquisition and aggregation of offshore wind power by multiterminal voltage-source HVDC," IEEE Trans. Power Del., vol. 18, no. 1, pp. 201-206, Jan. 2003. 
[16] K. H. Chan, J. A. Parle, N. Johnson, and E. Acha, "Real-time implementation of a HVDC-VSC model for application in a scaled-down wind energy conversion system," in Proc. Inst. Elect. Eng. AC-DC Power Transmission Conf., Nov. 2001, pp. 169-174, Publ. no. 485.

[17] M. Madrigal and E. Acha, Power Systems Harmonics-Computer Modelling and Analysis. New York: Wiley, 2002, ch. 16, pp. 337-359.

[18] M. Madrigal, "Modeling of power electronics controllers for harmonic analysis in power systems," Ph.D. dissertation, Dept. Electron. Elect. Eng., Univ. Glasgow, Glasgow, Scotland, Dec. 2001, Chap. 4, pp. 47-60.

[19] G. N. Bathurst, N. R. Watson, and J. Arrillaga, "Modeling of bipolar HVDC links in the harmonic domain," IEEE Trans. Power Del., vol. 15, no. 3, pp. 1034-1038, Jul. 2000.

Chang Hsin Chien (S'06) received the M.Sc. degree in power mechanical engineering from National Tsing Hua University, Hsinchu City, Taiwan, R.O.C., and is currently pursuing the Ph.D. degree in mechanical engineering at the University College London, where he joined the Offshore Power Research Group in 2003 .

He was a Chief Research and Development Engineer with the Electronic Engineering Department of Surtec Industry, Inc., Keelung City, Taiwan. His research has predominantly been in the field of harmonic analysis in subsea power cables suited for offshore power generation systems.

Mr. Chien is a member of the Institute of Engineering and Technology and the Institute of Marine Engineering, Science and Technology (IMarEST).
Richard W. G. Bucknall received the Ph.D. degree in electrical engineering from the Royal Naval Engineering College, Plymouth, U.K.

Currently, he is a Senior Lecturer and Course Director of the M.Sc. marine engineering and the M.Sc. Power Systems Programs at University College London (UCL), London, U.K. He joined UCL as a Lecturer in 1995 and was promoted to Senior Lecturer in 2002. He was a Marine Engineering Officer with BP.

Dr. Bucknall is a member of the Department's Marine Systems Research Group and leads the Offshore Power Research Group. He is a member of the Society of Naval Architects and Marine Engineers and the Institute of Engineering and Technology, and a Fellow member of the Institute of Marine Engineering, Science and Technology, U.K. 